Pakistan Journal of Humanities and Social Sciences

October - December 2019, Volume 7, No. 4, Pages 357 - 363

\title{
Impact of Optimism and Personal Growth Initiative on Positive Interpretation of Illness in Asthma Patients
}

\author{
Qurat Ul Ain ${ }^{1}$ \\ ${ }^{1}$ Institute of Applied Psychology, University of the Punjab, Lahore, Pakistan. \\ Email: quratulainannie06@gmail.com
}

\begin{abstract}
The prime purpose of recent study was to analyze the relationship of optimism, personal growth initiatives and positive interpretation of illness. This study considered this relationship with special focus on patients of asthma. Purposive sampling was used to collect the data from asthma patients. Pearson coefficient of correlation and Hierarchical regressions were used to examine the data. Recent results revealed that personal growth initiative have positive impact on positive interpretation of illness. But optimism was not found to be associated with optimism with positive interpretation of illness in asthma patient.
\end{abstract}

Keywords: Optimism, Personal Growth Initiative,0Positive interpretation of illness

\section{Introduction}

Asthma is a long term disease in its chronic form. In chronic form of asthma air channels become inflamed and narrow. Asthma is characterized by the symptoms such as; the patient coughs especially at night and in early in the morning, periods of civilation, problem in breathing and coughing and he feels his chest tightened. Affects of asthma were different in case to case. Every patient showed different reaction to the causes of asthma. That is why the perception could be entirely different too (Szeftel \& Schiffmen, 2012).

Optimism is a way which helps a man considering and observing things. The people who have optimistic views in life do not see the negative prospects of life and they always hope for positive results. They always have a faith in themselves to get things better.A sense of getting things in a better situation in future and positive feelings about fulfilling desires and hopes is called optimism (Austin \& Vancouver, 1996).Beck (2006, 1979); Ellis and Harper (1975) developed a cognitive therapy model in which they said that optimism may also be utilized for the eradication of depression. This model is actually not for teaching methodology of optimism but merely reduced the consequences of pessimism.Studies showed that optimistic person would positively interpret their illness (Beck, 2006; Carver 2010; Peterson 
\& Steen, 2009; Seligman, 1991; Nes \& Segerstrom, 2006 ;Schou, 2005; Matthews, Raikkonen, Sutton \& Kuller, 2004; Forgeard \& Seligman, 2008; Magyar-Moe, Carlstrom, Cohen, and Boediman, 2003).

Personal growth initiative is considered as person's constant and deliberate change on a cognitive and behavioral level (Hardin, Weigold, Robitschek \& Nixon, 2007).Personal growth can be divided in three aspects; (i).Undeliberately and out of conscious growth. (ii) Undeliberately but conscious growth.(iii).Deliberately and conscious growth. Intentional Growth has three salient features: information of and concerning the process of personal growth, value the procedure of personal growth, and deliberate Behavior (Robitschek, 1999).Recent research on Personal Growth Initiative has identified four areas to the intentional personal growth process. (i) Planfulness.(ii) willingness for change. (iii)by means of resources. iv) intended behavior. (Robitschek, 1986).2000). Different researches showed that all the patients who take initiative for their personal growth and health could also positively interpret their illness (Hardin, 2007; Hemant \& Ritu, 2010; Robitschek \& Kashubeck, 1999; Hardin \& Robitschek, 2007; Sharma, Santosh, Garg, Pooja, Rastogi \& Renu, 2009).

Positive interpretation of illness ,to some extent, can be called delusion, involving either making or changing a complete set of habits regarding bad situation (Tylor, 2001). According to Helson (1964), when individuals experiences become extreme negative, their neutral point turns into more negative so that positive interpretations are made of previously negative experiences. As a result, illness may turn other experiences looking more positive (Seligman \& Peterson, 1989).In short, it is summarized that most of previous literature stated that optimism and Personal growth initiative are linked positively to each other, because a person with personal growth initiative has positive expectation about their health and life. Different findings of studies were (Robitschek, 1998; 1986.,Egan, 2007., Kashdan, 2004) also in the favor of optimism and positive interpretation of illness.

This study would helpful in finding the role of optimistic thinking and individual's own caring regarding positive interpretation of their illness. Second important factor that leaded to conduct this study that there was less work on the area of asthma in Pakistan and the people with chronic disease like Asthma.

Hypothesis of the study are as;

- Optimism and Personal growth initiative is positively related with positive interpretation of Illness in patients with asthma. 
Pakistan Journal of Humanities and Social Sciences, 7(4), 2019

- Optimism and Personal Growth Initiative are likely to be positive predictors of positive interpretation of illness in patients with asthma.

\section{Method}

\subsection{Sample}

The sample was comprised of $(\mathrm{N}=100)$ with the range of $25-70,(\mathrm{M}=45.01, \mathrm{SD}=$ 13.80) were taken from government hospitals. Both men and women were included. Within subject research design and purposive sampling strategy was used to carry out the research. Inclusion criteria were; minimum duration of asthma was 3 years, ability to read and understand Urdu. All outdoor patients were included. Patients who were below 25 and above 70 , self diagnosed and with other physiological and psychological problems were excluded. Data was collected after taking formal permission from concerned authorities and after taking consent. Instructions were given to the participants and set of questionnaires were provided. The response rate to fill that questionnaire was 76 percent. All the ethical issues were kept in mind during the data collection.

\subsection{Assessment measures}

Optimism was assessed by Life Orientation Test Revised (LOT)-R (Scheier\& Carver, 1985). The LOT-R consisted of 8 coded items, plus fillers. Item number 3, 7 and 9 was reversely scored. Item number 2, 5, 6, 8 were the fillers items only. Half Items were framed in an positive way, half in a negative manner, and participants indicate their amount of agree or disagree with each point on a multi-point scale. The LOT-R had good psychometric properties, in most respects. In this research Researcher used the translated edition of this scale with the permission of author.The reliability of the entire item scale is $(\infty=0.95)$ which indicates the scale is reliable(Scheier\& Carver, 1985).

The Personal Growth Initiative Scale was a self-report tool that measures personal growth initiative.. The PGIS consisted of nine items that were rated on a Likert scale from $1=$ Strongly Disagree to $6=$ Strongly Agree. Scores of items were summed for the total score. Reliability and validity proof had been strong. Four subscales of personal growth initiative were as follows. (i)willingness for change subscale includes Item no. 2,8,11,16.(ii) Planfulness subscale includes item no. , 3, 5, 10, 13. (iii) Using resources subscales includes Item no. 6, 12, 14.(iv) Intentional behavior scale includes Item no. 4, 7, 9, 15. Those who scored more on the scale had an tendency for growth, while those low down on the scores was not purposely investigate out for the growth system. In this research researcher used the translated version of this scale with the permission of this author (Robitschek,1999). 
The Silver Linning Questionnaire measured the degree to which people thought their illness had a positive advantage in spite of the negative consequences of being ill. Its position in healing from illness was difficult (Michael \&Hyland, 1997). Questionnaire consisted of 38 items. Its ratingscale was between $5=$ Strongly agree, and $1=$ Strongly disagree. In this research researcher used the translated version (Huda \&Kauser, 2012) of Silver lining questionnaire.

\section{Results}

The current research explores the positive relationship between Optimism, Personal growth initiative and positive interpretation of illness in patients with asthma. The main analysis implicated performing: (i) Reliability and descriptive analysis to assess psychometric properties of the scales; (ii) Pearson product correlation was used to analyze the relationship between the variables.

Table 1: Correlation Analysis

\begin{tabular}{|c|c|c|c|c|c|}
\hline Variables & $\mathbf{1}$ & $\mathbf{2}$ & $\mathbf{3}$ & $\mathbf{M}$ & SD \\
\hline 1. LOT & - & .17 & .15 & 2.2 & .33 \\
\hline 2. PGI & & - & $.52^{* *}$ & 2.9 & .78 \\
\hline 3. SLQ & & & - & 3.2 & .63 \\
\hline
\end{tabular}

Note: $* * \mathrm{p}<.01, \mathrm{LOT}=$ life orientation test; PGI = personal growth initiative; SLQ = silver lining questionnaire.

Results reported in the above table 1 showed that optimism, personal growth initiative and positive interpretation of illness were positively related to each other, but optimism and positive interpretation of illness were not related to each other. It showed that the hypothesis was partially accepted.

Hierarchical regression analysis was carried out to find the predictors for positive interpretation of illness after controlling age, gender, sleep disturbance and severity of disease. Results reported in table 2 revealed that significantly predicting variable was Personal Growth Initiative after controlling desired variables. In block one for positive interpretation of illness, demographic variables; gender and age were controlled. In block two for positive interpretation of illness, sleep disturbance and severity of disease were controlled. Results revealed that sleep disturbance and severity of disease were not significantly predicted the positive interpretation of illness. Findings showed that only Personal Growth Initiative positively predicted the Positive Interpretation of Illness. 
Table 2: $\quad$ Hierarchical Regression analysis for predictors of Positive Interpretation of Illness

\begin{tabular}{|c|c|c|c|c|c|c|c|c|c|}
\hline \multirow[t]{2}{*}{ Predictors } & \multicolumn{3}{|c|}{ Block 1} & \multicolumn{3}{|c|}{ Block 2} & \multicolumn{3}{|c|}{ Block 3} \\
\hline & $\mathrm{B}$ & SE & $\mathrm{B}$ & $\mathrm{B}$ & SE & $\beta$ & $\mathrm{B}$ & SE & $\beta$ \\
\hline Constant & 3.09 & & & 2.95 & & & 1.28 & & \\
\hline Age & 0.01 & 0.01 & 0.18 & 0.01 & 0.01 & 0.13 & 0.01 & 0.01 & 0.15 \\
\hline Gender & -0.16 & 0.13 & -0.13 & -1.12 & 0.13 & -0.10 & -0.05 & 0.11 & -0.04 \\
\hline \multicolumn{10}{|c|}{ Sleep disturbance } \\
\hline Low vs. mild disturbance & & & & -0.10 & 0.22 & -0.07 & -0.18 & 0.19 & -0.12 \\
\hline Low vs. moderate disturbance & & & & 0.23 & 0.21 & 0.18 & 0.09 & 0.18 & 0.07 \\
\hline Low vs. high disturbance & & & & -0.14 & 0.22 & -0.09 & -0.32 & 0.19 & -0.22 \\
\hline \multicolumn{10}{|c|}{ Severity of disease } \\
\hline Low vs. high in day & & & & 0.13 & 0.26 & 0.09 & 0.17 & 0.22 & 0.12 \\
\hline Low vs. moderate in day & & & & -0.39 & 0.27 & -0.28 & -0.22 & -0.24 & -0.16 \\
\hline Low vs. mild in day & & & & -0.11 & 0.26 & -0.01 & -0.08 & 0.22 & -0.06 \\
\hline Low vs. high in night & & & & 0.27 & 0.31 & 0.21 & 0.45 & 0.27 & 0.34 \\
\hline Low vs. moderate in night & & & & 0.14 & 0.31 & 0.09 & 0.30 & 0.27 & 0.20 \\
\hline Low vs. mild in night & & & & 0.43 & 0.30 & 0.33 & 0.51 & 0.26 & 0.40 \\
\hline Optimism & & & & & & & 0.13 & 0.17 & 0.07 \\
\hline Personal Growth Initiative & & & & & & & 0.40 & 0.07 & $0.45 * *$ \\
\hline$\Delta \mathbf{R}^{2}$ & 0.60 & & & 0.12 & & & $0.24 * * *$ & & \\
\hline
\end{tabular}

Note: sleep disturbance: For low vs. mild disturbance; low $=0$, mild $=1$; for low vs. moderate; low $=0$, moderate $=1$; for low vs. high; low =0, high = 1; Severity of disease in day time: for low vs. high in day; low =0, high = 1; for low vs. moderate in day; low $=0$, moderate $=1$; for low vs. mild in day; low $=0$, mild $=1$; severity of disease in night: for low vs. high in night; low $=0$, high $=1$; for low vs. moderate in night; low $=0$, moderate $=1$; for low vs. mild in night; low $=0$, mild $=1, * * p<.01$, ***p<.001

\section{Discussions}

The present research aimed to examine the relationship between optimism, personal growth initiative and positive interpretation of illness in asthmatic patients. It was expected that the asthmatic patients who were optimistic could positively interpret their illness. The results of the research exposed that there were positive relationship between personal growth initiative and positive interpretation of illness and personal growth initiative also predict the positive interpretation of illness. However results showed that there was no relationship between optimism and positive interpretation of illness.

It was hypothesized that patients with high optimism could interpret their illness in a positive way and optimism also predict the positive interpretation of illness. The results of research by Hurt, Burn, Hindle, Sameul, Wilson \& Brown (2010) supports the results of the present research that positive interpretation of illness is not always essential for the patients who are optimists. According to the results optimism did not positively predict the positive interpretation of illness.

Another research made by Denis, Marijda and Jozen proved that the patients who are in an acute stage of illness do not take a slanted idea about their health, and they move towards a behavior which is self-caring. Contrary to this, a recent research showed that it was 
not necessary that the patients who had optimistic thinking might tackle their illness positively.

According to a research made by Patrie,Jago,Daniel and Devcich (2007) a patient faces some types of circumstances which hinder him from a positive thinking about his illness. These factors were like name of disease and the condition in which patient is going through. Another factor which affects is faith and belief concerning start and duration of disease. Patient's beliefs are generated by the views of the people who are involved in his treatment. Trying to know about patient's own notions about his disease is never considered important from doctor's end. Another interesting factor is that every patient has his own views about disease. Therefore, a similar disease can be seen differently by two different patients. The results of present study are supported by this research, that's why there is a insignificant relationship between optimism and positive interpretation of illness.

It was hypothesized that personal growth initiative and positive interpretation of illness are related to each other and personal growth initiative also predict the positive interpretation of illness. The results of present study were significant. The outcome of present study are consistent with the work of Albrecht and Devlieger, (1999); Sodergren and Hyland (2000). which proved that diseased people often show positive results of sickness, there can occur a healthy relationships, a better quality of life and positive personality changes, personal growth initiative.

\section{Conclusion}

It was concluded that there personal growth initiative positively related as well as positively predicted positive interpretation of illness in patients with asthma while optimism was not found to be considerable predictor of positive interpretation of illness in patients with Asthma. It has some limitations like; problem of sample restriction because mostly hospitals did not permit to collect data from there and variables like Well-being may influence the perception of illness in patients. It has some implications like different kinds of counseling strategies are suggested to study for female and male asthmatic patients to produce optimistic approach, On the basis of research outcome consciousness can be given to the patients. Moreover, it has implications for the doctors, family and medical staff of the hospitals to help the patients to develop the positive interpretation of illness. 


\section{References}

Austin, J. T., \& Vancouver, J. B. (1996). Goal constructs in psychology: Structure, process, and content. Psychological Bulletin, 120, 338-375. Retrieved from http://psycnet.apa.org/index.cfm?fa=buy.optionToBuy\& id=1996-01405-002.

Beck, A. T. (2006). How an anomalous finding led to a new system of psychotherapy. Nature Medicine, 12, 1139-1141. doi:10.1038/nm1006-1139.

Carver, C., Scheier, M., Segerstrom, S., (2010).Optimism. Clinical psychology review, 30, 879-889. doi:10.1016/j.cpr.2010.01.006.

Hardin, E. E., Weigold I. K., Robitschek, C., \& Nixon, A. E. (2007). Self-discrepancy and distress: The role of Personal Growth Initiative. Journal of Counseling Psychology, 54, 86 - 92. doi: 10.1037/0022-0167.54.1.86.

Sodergren, S. C. \& Hyland, M. E. (1997). Qualitative phase in the development of the Silver Lining Questionnaire. Quality of Life Research, 6, (7-8), 365.Retrieved from http://www.ppc.sas.upenn.edu/ppquestionnaires.htm\#SLQ.

Peterson, C. (2000). The future of optimism. American Psychologist. 55(1), 44-55. doi: $10.1037 / 0003-066 X .55 .1 .44$

Robitschek, C. (1999). Further validation of the Personal Growth Initiative Scale. Measurement and Evaluation in Counseling and Development, 31, 197-210. Retrieved from http://psycnet.apa.org/psycinfo/1999-00658-002.

Schou, I., Ekeberg, O., \&Ruland, C.M. (2005).The mediating role of appraisal and coping in the relationship between optimism-pessimism and quality of life. PsychologyOncology, 14, 718-727. Retrieved from http://www.ncbi.nlm.nih.gov/pubmed/15669084.

Segerstrom, S. C. (2006). How does optimism suppress immunity? Evaluation of three affective pathways. Health Psychology, 25, 653-657. doi: 10.1037/02786133.25.5.653.

Schiffman, G.,\&Szeftel, A. (2012). What asthma medications to use. Medicine Net. Retrieved from:http://www.medicinenet.com/asthma/page9.htm\#what_medications_are_used_i n_the_treatment_of_asthma 